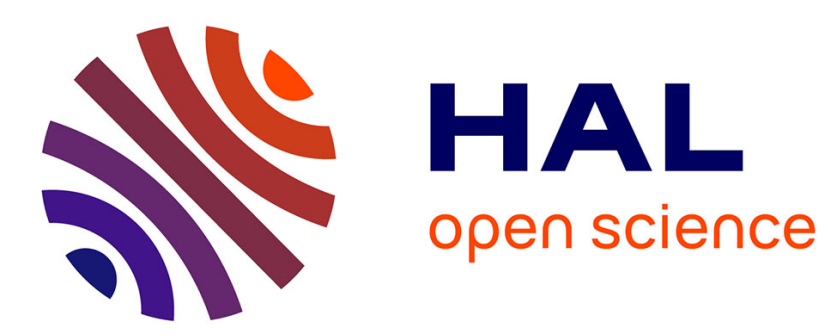

\title{
Radio frequency magnetron sputtering deposition of hetero-epitaxial strontium barium niobate thin films (SrxBa1-xNb2O6)
}

Mireille Cuniot-Ponsard, Jean-Michel Desvignes, Buntha Ea-Kim, Eric Leroy

\section{- To cite this version:}

Mireille Cuniot-Ponsard, Jean-Michel Desvignes, Buntha Ea-Kim, Eric Leroy. Radio frequency magnetron sputtering deposition of hetero-epitaxial strontium barium niobate thin films (SrxBa1xNb2O6). Journal of Applied Physics, 2003, 93 (3), pp.1718-1724. 10.1063/1.1535749 . hal-00871187

\section{HAL Id: hal-00871187 \\ https://hal-iogs.archives-ouvertes.fr/hal-00871187}

Submitted on 9 Oct 2013

HAL is a multi-disciplinary open access archive for the deposit and dissemination of scientific research documents, whether they are published or not. The documents may come from teaching and research institutions in France or abroad, or from public or private research centers.
L'archive ouverte pluridisciplinaire HAL, est destinée au dépôt et à la diffusion de documents scientifiques de niveau recherche, publiés ou non, émanant des établissements d'enseignement et de recherche français ou étrangers, des laboratoires publics ou privés. 


\title{
Radio frequency magnetron sputtering deposition of hetero-epitaxial strontium barium niobate thin films $\left(\mathrm{Sr}_{x} \mathrm{Ba}_{1-{ }_{x}} \mathrm{Nb}_{2} \mathrm{O}_{6}\right)$
}

\author{
M. Cuniot-Ponsard, ${ }^{\text {a) }}$ J. M. Desvignes, and B. Ea-Kim \\ Laboratoire Charles Fabry de l'Institut d'Optique, UMR 8501 du CNRS, Ecole Supérieure d'Optique, \\ Bât 503, Centre Universitaire Paris Sud, 91403 Orsay Cedex, France \\ E. Leroy \\ Laboratoire de Chimie Métallurgique des Terres Rares, UPR 209 du CNRS, 2-8 rue Henri Dunant, 94320 \\ Thiais, France
}

(Received 29 July 2002; accepted 13 November 2002)

\begin{abstract}
Excellent electro-optic properties of $\mathrm{Sr}_{x} \mathrm{Ba}_{1-x} \mathrm{Nb}_{2} \mathrm{O}_{6}$ crystals (SBN:x) motivate the attempts to control the deposition of high ordered SBN thin films with the aim of optical waveguiding and processing integration. We have examined the ability of sputtering techniques to deposit stoichiometric SBN thin films. Composition analysis has enabled us to probe the mechanisms which control the target-film composition transfer and to define an experimental strategy for stoichiometry control. Epitaxial (001) SBN thin films have been obtained on $\mathrm{MgO}$ (100) substrates, which exhibit two in-plane orientations $\left( \pm 31^{\circ}\right)$ mirror symmetric to the $\mathrm{MgO}$ cell axis. (c) 2003 American Institute of Physics. [DOI: 10.1063/1.1535749]
\end{abstract}

\section{INTRODUCTION}

Bulk $\mathrm{Sr}_{x} \mathrm{Ba}_{1-x} \mathrm{Nb}_{2} \mathrm{O}_{6}$ (SBN: $x$ ) is an excellent ferroelectric material which has been widely studied for holographic recording and optical processing. The monocrystalline SBN solid solution exhibits one of the largest known linear electro-optic coefficients ( $r_{33} \approx 1300 \mathrm{pm} \mathrm{V}^{-1}$ for SBN:75), nearly two orders of magnitude larger than that of the primary electro-optic material $\mathrm{LiNbO}_{3}$. The growth of thin and highly ordered SBN films is expected to allow integrated signal waveguiding and processing by application of voltages about 1000 times lower than that required in the case of SBN bulk crystals. However the realization of the excellent electro-optic properties of SBN requires a successful heteroepitaxial growth of the film with the (001) SBN direction perpendicular to the lattice-matched substrate plane.

The objective of this research was to determine if radio frequency magnetron sputtering can be used to deposit epitaxial thin films of this material for use in integrated electrooptics.

There have been limited reports on the growth of epitaxial SBN thin films by various techniques such as metalorganic chemical vapor deposition (MOCVD), ${ }^{1,2}$ pulsed laser deposition (PLD), ${ }^{3-7}$ plasma enhanced-CVD, ${ }^{8}$ sol-gel process, ${ }^{9-10}$ and combination of sol-gel and PLD. ${ }^{11}$ Good non linear optical properties have been reported for films produced by MOCVD (second-harmonic generation) ${ }^{2}$ and $\operatorname{PLD}\left(r_{33}=350 \mathrm{pm} / \mathrm{V}\right) .{ }^{4}$ Very few reports were published on the use of magnetron sputtering to deposit such oxides. ${ }^{12-15}$ Due to the complicated chemistry of this material, one of the main difficulties of the SBN thin film growth lies in the essential control of the film stoichiometry.

\footnotetext{
a)Electronic mail: mireille.cuniot@iota.u-psud.fr
}

This paper analyzes the mechanisms of SBN sputtering deposition, and suggests a strategy for experimental control of thin film stoichiometry.

\section{EXPERIMENT}

Thin amorphous SBN films were deposited by rf magnetron sputtering of polycrystalline targets SBN: $x(x=48 \%$ and $67 \%$ ), at $250^{\circ} \mathrm{C}$ substrate temperature and $5 \times 10^{-3}$ mbar $\left(\mathrm{Ar}+\mathrm{O}_{2}\right)$ plasma pressure, on $\mathrm{MgO}$ (100) substrates. The choice of the substrate was guided by the required film crystallographic orientation and waveguiding properties. The lattice mismatch between SBN:x (001) and $\mathrm{MgO}$ (100) increases with the $\mathrm{Sr} / \mathrm{Ba}$ ratio from $0.9 \%$ until $1.3 \%$ and the difference in refraction index $\Delta n=n_{\mathrm{SBN}}-n_{\mathrm{MgO}}$ is close to 0.5 at $\lambda=1.5 \mu \mathrm{m}$. The amorphous films were then crystallized in situ under vacuum $\left(2 \times 10^{-7}\right.$ mbar $)$ by using halogen lamps. The crystallization temperature was fixed in the range $650-850^{\circ} \mathrm{C}$ and kept constant during two hours.

Disregarding the target-film composition transfer, which was a priori unknown, the selection of the targets $\mathrm{Sr} / \mathrm{Ba}$ ratio was based on the expected compromise between the properties this ratio is known to greatly affect. On the one hand increasing the $\mathrm{Sr} / \mathrm{Ba}$ ratio in the bulk solid solution has been established to greatly improve the electro-optic properties; ${ }^{16}$ however this also threatens the phase stability due to the correlated decrease in the Curie temperature ${ }^{16}\left(T_{c} \approx 50^{\circ} \mathrm{C}\right.$ for $x=75 \%$ ), and worsens the lattice mismatch as mentioned earlier.

Target and film compositions were determined by electron microprobe analysis using a single crystal of known composition (SBN:60) as a standard. Depending on its magnitude, the film thickness was determined from either spectrophotometry transmission or $\mathrm{x}$-ray reflectometry measurements. X-ray $\left(\mathrm{Cu} K_{\alpha 1}\right)$ diffraction techniques (XRD) were used to identify crystalline structure and orientation. 


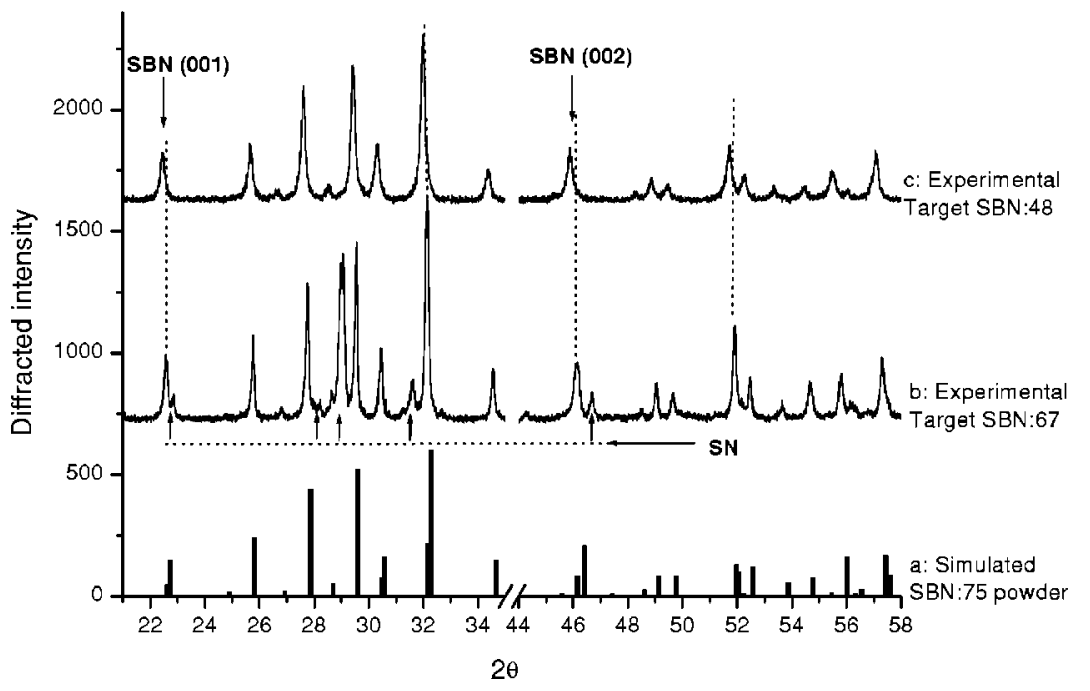

FIG. 1. Simulated x-ray $\theta-2 \theta$ scan of a tungsten bronze SBN:75 structure (a) and experimental $\mathrm{x}$-ray $\theta-2 \theta$ scans performed on two polycrystalline targets SBN:67 (b) and SBN:48 (c).

\section{THE X-RAY DIFFRACTION TRAPS}

Compared to the x-ray $\theta-2 \theta$ patterns of polycrystalline SBN: $x$ (Fig. 1), a (001) oriented SBN film is expected to display only the two peaks arrowed in Fig. 1 at $2 \theta \approx 22.5^{\circ}$ and $45.9^{\circ}$. We simulated (Fig. 1(a)) the powder x-ray spectrum from the reported tetragonal tungsten bronze (TTB) SBN:75 structure. ${ }^{17}$ A very satisfying agreement may be noted between this calculated spectrum and the experimental $\theta-2 \theta$ scan of the SBN:48 target (Fig. 1(c)). Increasing the $\mathrm{Sr} / \mathrm{Ba}$ ratio from $48 / 52$ to $67 / 33$ (Fig. 1(b)) systematically causes the rise of parasitic peaks that we have unambiguously identified as issuing from the phase $\mathrm{SrNb}_{2} \mathrm{O}_{6}$, denoted $\mathrm{SN}$ in Fig. 1 and in the following ( $\mathrm{S}$ for $\mathrm{SrO}$ and $\mathrm{N}$ for $\mathrm{Nb}_{2} \mathrm{O}_{5}$ ). This points out the difficulty encountered to prepare a Sr rich SBN single phase, a difficulty more generally illustrated in the phase diagram shown in Fig. 2. As brought into relief by vertical dotted lines (Figs. 1(b) and 1(c)), an in-

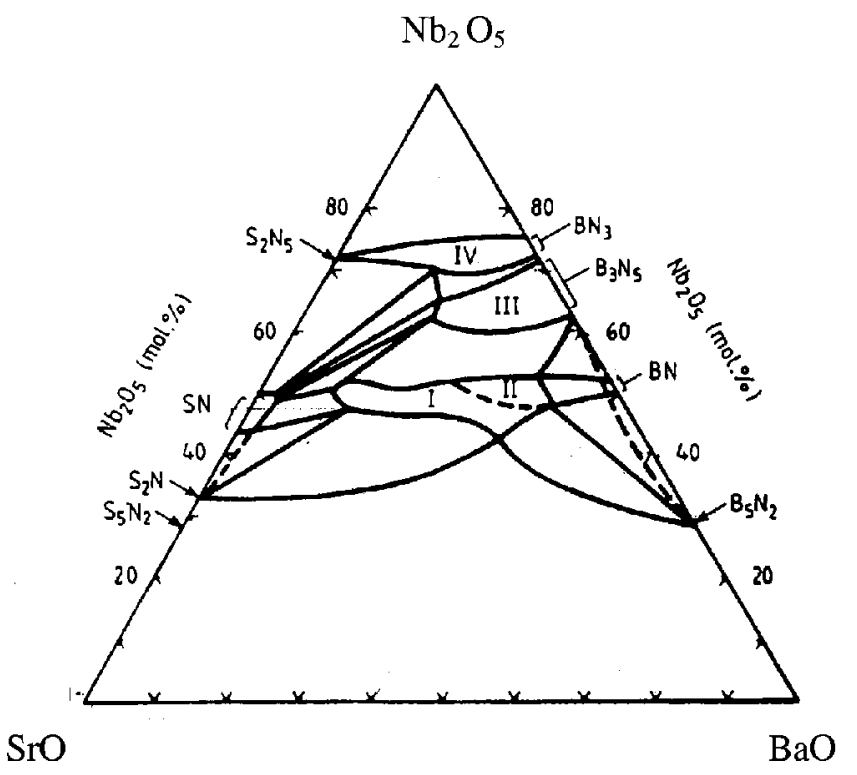

FIG. 2. [Ref. 18] Ternary phase relationships in the room temperature isotherm of the system $\mathrm{BaO}-\mathrm{SrO}-\mathrm{Nb}_{2} \mathrm{O}_{5}$, respectively denoted $\mathrm{B}-\mathrm{S}-\mathrm{N}$ in the chemical formula given along the axes. crease in the $\mathrm{Sr}$ content results as expected in a slight shift of the SBN peaks toward higher $2 \theta$ values due to the lower size of $\mathrm{Sr}$ compared to $\mathrm{Ba}$ atom and to the subsequent decrease in the lattice constants.

In the ternary phase diagram shown in Fig. 2 and established by bulk crystal growth specialists, ${ }^{18}$ the existence region of the TTB SBN bulk material is denoted I. Although this diagram is only suggestive for thin film growth issues, one may notice the numerous close phases which crystallize as soon as the $(\mathrm{Sr}+\mathrm{Ba}) / \mathrm{Nb}$ ratio deviates from the stoichiometric value 0.5. Some of these phases $\left(\mathrm{Sr}_{2} \mathrm{Nb}_{10} \mathrm{O}_{27}\right.$, $\mathrm{BaNb}_{2} \mathrm{O}_{6}, \mathrm{BaNb}_{6} \mathrm{O}_{16}, \mathrm{Ba}_{3} \mathrm{Nb}_{10} \mathrm{O}_{28}$, respectively denoted $\mathrm{S}_{2} \mathrm{~N}_{5}, \mathrm{BN}, \mathrm{BN}_{3}$, and $\mathrm{B}_{3} \mathrm{~N}_{5}$ in the diagram) have a c-cell parameter very close to that of the TTB SBN phase and consequently diffract their (001) and (002) peaks in very close angular locations as illustrated in Fig. 3 (experimental data in Fig. 3 issue from the JCPDS-International Center for Diffraction Data). The other cell parameters of these parasitic phases are also close to those (or to multiples) of the TTB SBN cell, so that the lattice-match and oriented (001) growth are similarly probable.

The search for the single SBN: $x$ phase and heteroepitaxial conditions that should be naturally guided by the XRD information is actually disoriented by confusing XRD patterns due to the mixing of phases close in cell shape and parameters. An increase in the relative intensity of a peak located about $2 \theta=22.5^{\circ}$ may result either from the desired (001) orientation of the SBN grains or from an increase in the volume fraction and/or orientation of any of the parasitic phases which diffract in this angular location. A shift in position may result from an epitaxial stress, from a change in the phases volume fractions and/or orientations, or equally from an evolution of the Sr content in the SBN phase (Fig. 1). Used alone, the XRD approach turns out to be an unreliable guide of the search. The help of composition analysis was essential in our investigation to avoid wrong conclusions.

An additional $\mathrm{x}$-ray indication of the presence of the TTB SBN phase may be sought from the ratio, denoted $r-1 / 2$, of the (001) to the (002) peaks intensities. This ratio is 


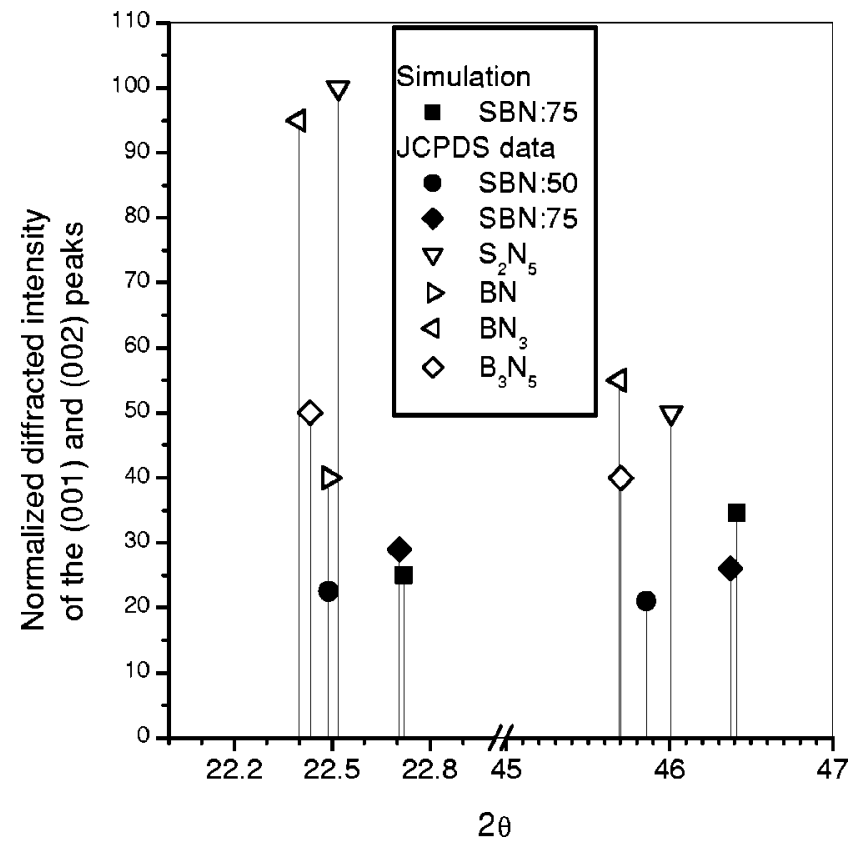

FIG. 3. Position and normalized diffracted intensity of the (001) and (002) peaks for the phases $\mathrm{S}_{2} \mathrm{~N}_{5}, \mathrm{BN}, \mathrm{BN}_{3}, \mathrm{~B}_{3} \mathrm{~N}_{5}$, and $\mathrm{SBN}$, from reported experimental data (JCPDS-International Centre for Diffraction Data) and calculated from the reported tetragonal tungsten bronze structure of SBN:75 (Ref. 17).

experimentally found equal to 0.9 and 1.08 in the cases of experimental SBN:48, SBN:67, and calculated to be 0.72 for SBN:75. This ratio should enable us to set $\mathrm{S}_{2} \mathrm{~N}_{5}$ and $\mathrm{BN}_{3}$, which display an $r-1 / 2$ two times larger, apart from the other possible phases.

\section{RESULTS}

\section{A. The mechanisms of the target-film composition transfer}

The mechanisms of the target-film composition transfer were probed by varying the rf power and the oxygen percentage in the plasma. The film compositions, as measured by electron microprobe analysis, are plotted in the ternary phase diagram of Fig. 4. A certain number of experimental findings stand out from these results. The first one is the low influence of $\mathrm{rf}$ power and oxygen percentage in the plasma on the $\mathrm{Sr} / \mathrm{Ba}$ ratio, which appears to be mainly determined by the target composition, suggesting similar properties of the $\mathrm{Sr}$ and $\mathrm{Ba}$ atoms in terms of sputtering yield and reactivity with oxygen. The second experimental finding is that the sputtering yield of niobium from the target is lower than that of the two other metallic atoms. This produces niobium deficient films when nonreactive sputtering is used (pure Ar plasma). The third experimental result is that oxygen in the plasma produces niobium-rich films. The important role of oxygen is further highlighted by the observed abrupt decay of deposition rate with oxygen percentage (Fig. 5). These results show the difficulty of achieving the stoichiometry transfer necessary for growth of a single phase SBN in such a sputtering system. Beyond a value of around 3\% oxygen, the deposition rate (Fig. 5) as well as the film composition are no longer influenced by the amount of $\mathrm{O}_{2}$ in the plasma. The latter

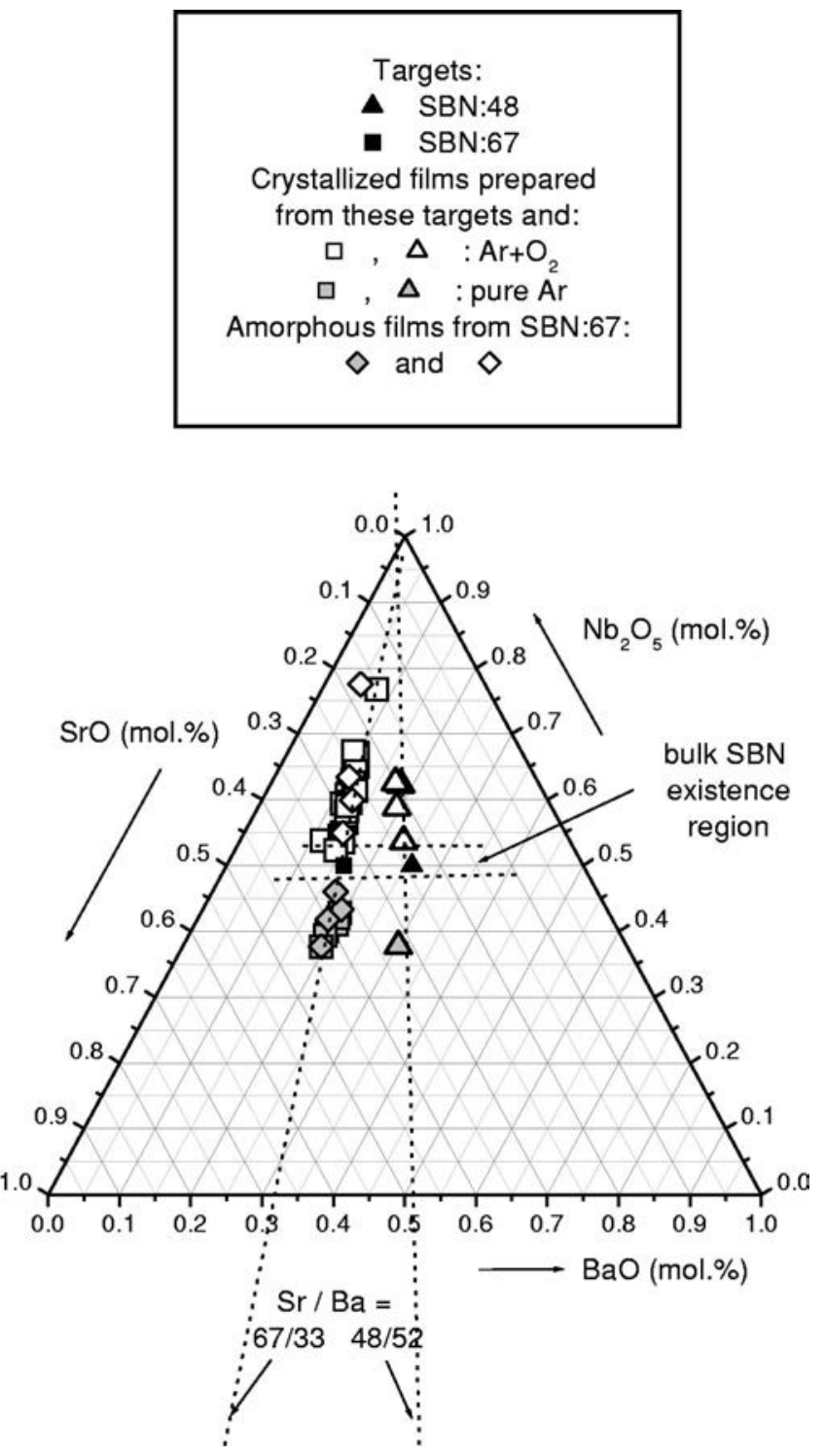

FIG. 4. Target and sputtered film compositions as determined from electron microprobe analysis. Differences in film composition have been obtained by varying rf power and oxygen percentage in the plasma. The other deposition parameters were fixed.

become dependent on $\mathrm{rf}$ power only which allows one to detail the influence on the film composition of this rf power, through the directly correlated deposition rate (Fig. 6). In both cases of nonzero and zero oxygen percentages in the plasma, the opposite deviations from the target stoichiometry depicted in Fig. 6 unambiguously decrease with increasing rf power. Therefore and as might be expected, increasing rf power reduces the differences between $\mathrm{Nb}$ and $(\mathrm{Sr}, \mathrm{Ba})$ sputtering yields but it is hazardous for the target integrity. Another way toward stoichiometry control consists in searching a compromise between $\mathrm{Nb}$ lack and $\mathrm{Nb}$ excess, based on the predicted existence of optimized ( $\mathrm{rf}$ power, $\% \mathrm{O}_{2}$ ) pairs (Fig. 6).

\section{B. Experimental stoichiometry approach}

An experimental approach to stoichiometry control consists in slightly increasing oxygen percentage in the plasma 


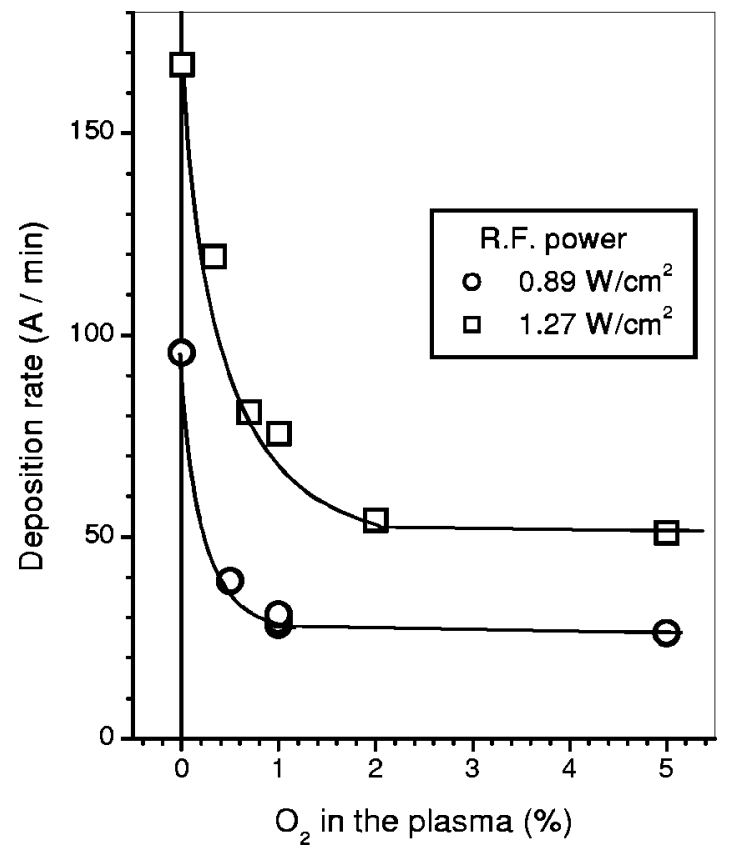

FIG. 5. Typical evolution of the sputtering deposition rate with oxygen percentage in the plasma at fixed rf power, all other deposition parameters being kept constant.

from zero in the very narrow range which separates $\mathrm{Nb}$ lack from $\mathrm{Nb}$ excess, at well fixed rf power and other preparation parameters. The x-ray diffraction $\theta-2 \theta$ patterns obtained from films so successively deposited are shown in Fig. 7 in the two limited angular ranges of interest for us, that is in the vicinities of $2 \theta=22.5^{\circ}$ (left-hand side of Fig. 7) and $45.9^{\circ}$ (right-hand side of Fig. 7). The films were prepared by using a SBN:48 target, fixing rf power $=1.3 \mathrm{~W} \mathrm{~cm}^{-2}$ and deposition time $=20 \mathrm{~min}$.

The film deviation from stoichiometry results as expected in the crystallization of parasitic phases. The easiest parasitic phase to identify is $\mathrm{SrNb}_{2} \mathrm{O}_{6}(\mathrm{SN})$ due to its unambiguous XRD peaks location, particularly (200) at $2 \theta=22.8^{\circ}$, (013) and $(211)$ at $2 \theta=29.1^{\circ},(400)$ at $2 \theta \approx 46.6^{\circ}$, as already shown in Fig. 1 for the SBN:67 target. On the MgO (100) substrates this phase $\mathrm{SN}$ is found to grow epitaxially and (200) oriented. Due to the logarithmic scale used in Fig. 7, a very low intensity $(12 \overline{4}) \mathrm{SN}$ peak at $2 \theta \approx 47.7^{\circ}$ appears alongside of the very intense (400) SN peak. The epitaxy relationship between $\mathrm{SN}$ and $\mathrm{MgO}$, analyzed through phiscan x-ray measurements, clearly indicates only two in-plane orientations, mirror symmetric $\left( \pm 45^{\circ}\right)$ to the axis of the $\mathrm{MgO}(100)$ cell.

In the angular location where the SBN (001) and (002) peaks are expected $\left(2 \theta \approx 22.5^{\circ}\right.$ and $\left.45.9^{\circ}\right)$, the XRD scans display three different successive evolutions. For oxygen percentages lower than $0.4 \%$ (Figs. $7(\mathrm{a})-7(\mathrm{~d})$ ), the ratio of the order 1 to the order 2 intensities, $r$-1/2, is measured close to 1.7 , which is not consistent with the SBN assumption: the observed intensity likely issues from one of the above mentioned parasitic phases which grows parallel and complementary to SN. For oxygen percentages in the range 0.4 $\rightarrow 3 \%$ [Figs. $7(\mathrm{e})-7(\mathrm{~h})$ ], this ratio $r-1 / 2$ turns to a very different value close to 0.8 , while the peaks shift toward higher $2 \theta$ values, and exhibit an intensity evolution inverse of that of the SN peaks with increasing oxygen. All these observations are consistent with the assumption of a SBN phase growing at the expense of the other competing phases when crossing SBN stoichiometry between Nb lack and Nb excess. For oxygen percentages higher than 2\% (Figs. 7(g) and 7(h)), both SBN and SN peak intensities decrease with increasing oxygen, although they do at very different rhythms. Electron microprobe analysis confirms these samples are already beyond stoichiometry and exhibit a $\mathrm{Nb}$ excess. If experimental evidence for parallel SBN growth and stoichiometry approach may be considered as satisfying, it is noticeable that, given our arbitrarily fixed other deposition parameters, sto-
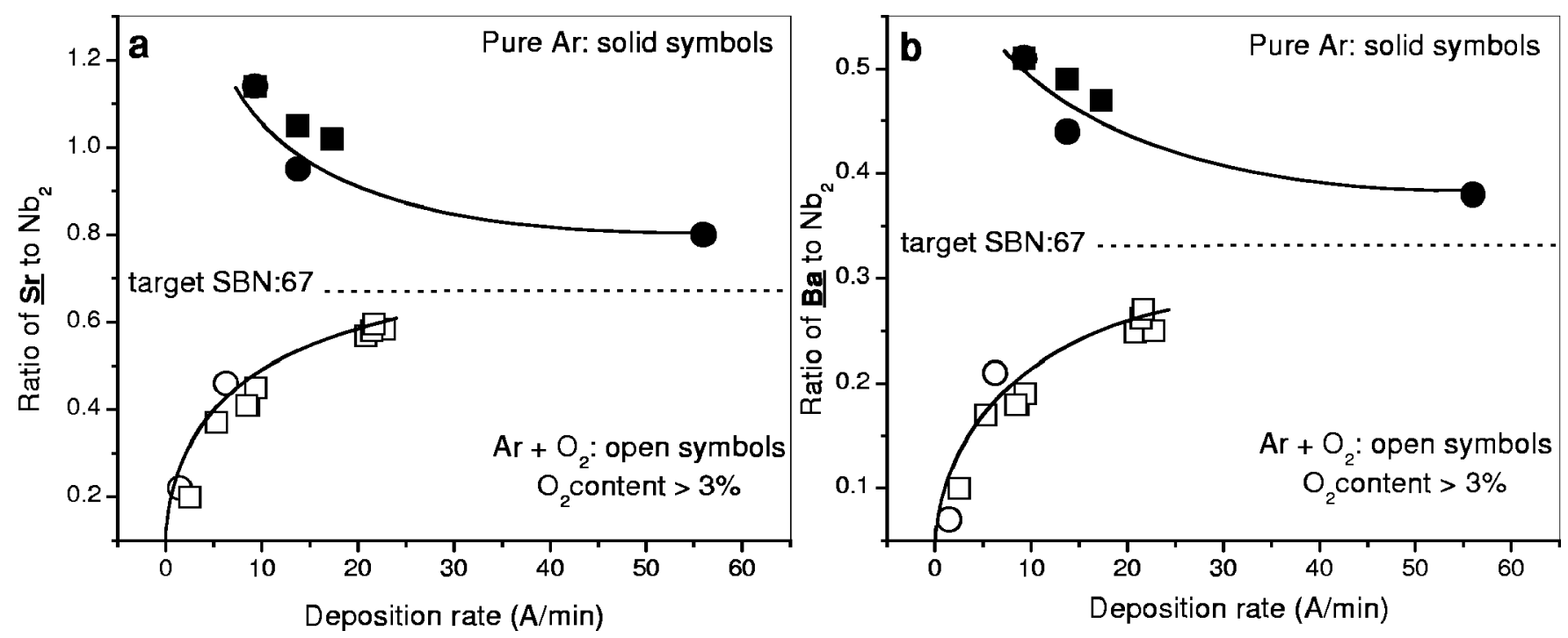

FIG. 6. Ratio of $\mathrm{Sr}$ (a) or $\mathrm{Ba}$ (b) to $\mathrm{Nb}_{2}$ in films sputtered from a $\mathrm{SBN}$ :67 target as a function of deposition rate when this deposition rate is exclusively varied by modifying rf power. Oxygen percentage in the plasma is either zero (closed symbols), or higher than 3\% (3\%-15\%) (open symbols), a range in which it affects neither the deposition rate nor the film composition. Amorphous and crystallized deposits are, respectively, represented with circular and square symbols. 

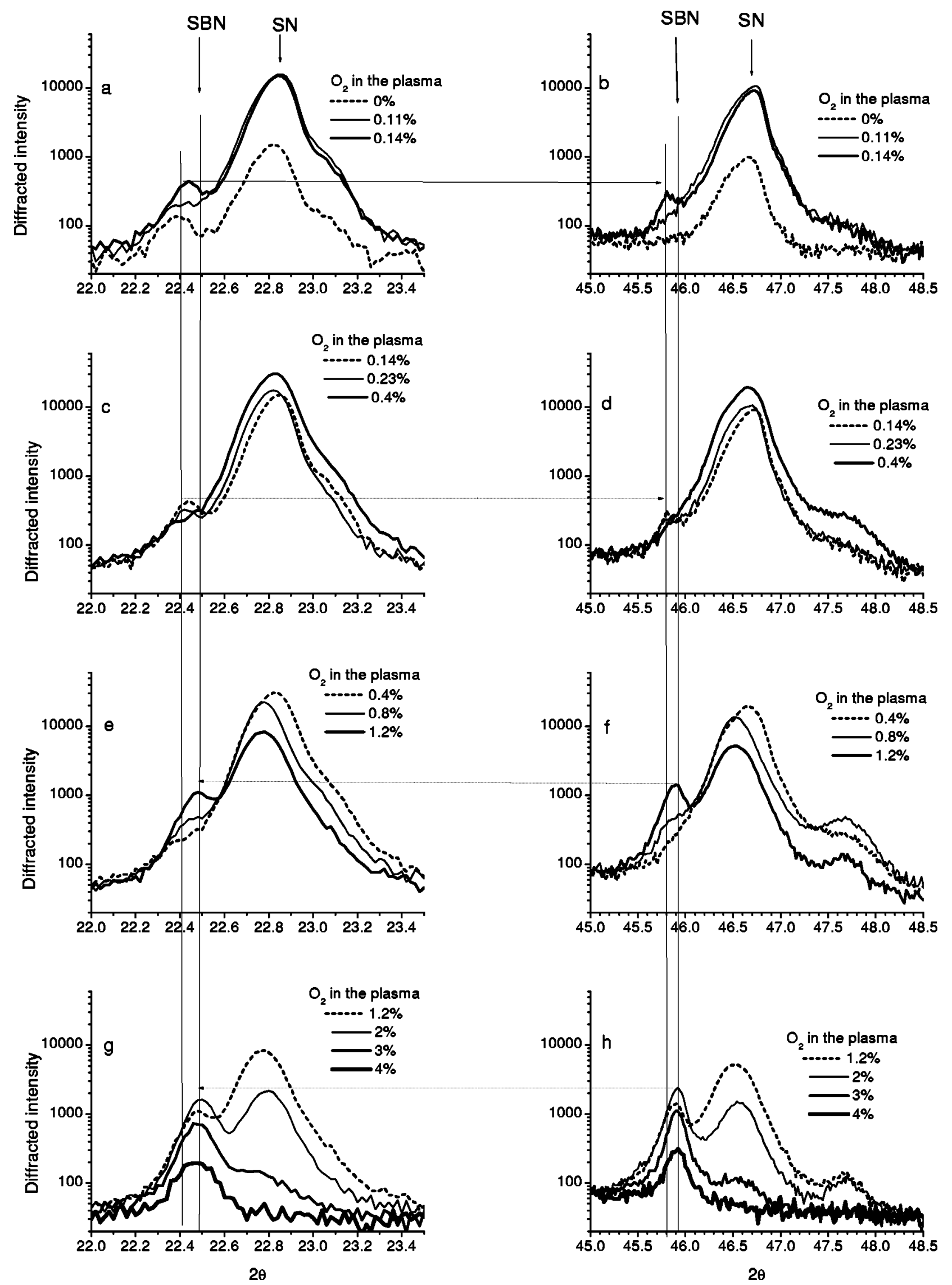

FIG. 7. Experimental x-ray diffraction $\theta-2 \theta$ patterns performed on thin films prepared from a SBN:48 target by increasing the oxygen percentage in the $(\mathrm{Ar}+\mathrm{O} 2)$ plasma from zero to $4 \%$, all other preparation parameters being kept constant. The patterns are shown in the vicinities of the $2 \theta$ angular locations of the SBN (001) and SN (200) peaks on the left-hand side $\left(22^{\circ}-23.5^{\circ}\right)$, and of the SBN (002) and SN (400) peaks on the right-hand side $\left(45^{\circ}-48.5^{\circ}\right)$. An identical logarithmic scale is used for each of the eight figures. Oxygen increases from top to bottom, and from dotted to solid to bold line. Vertical lines point out the angular shift of the concerned peak while horizontal lines point out the variation in the ratio of the order 1 to the order 2 peaks intensities. 


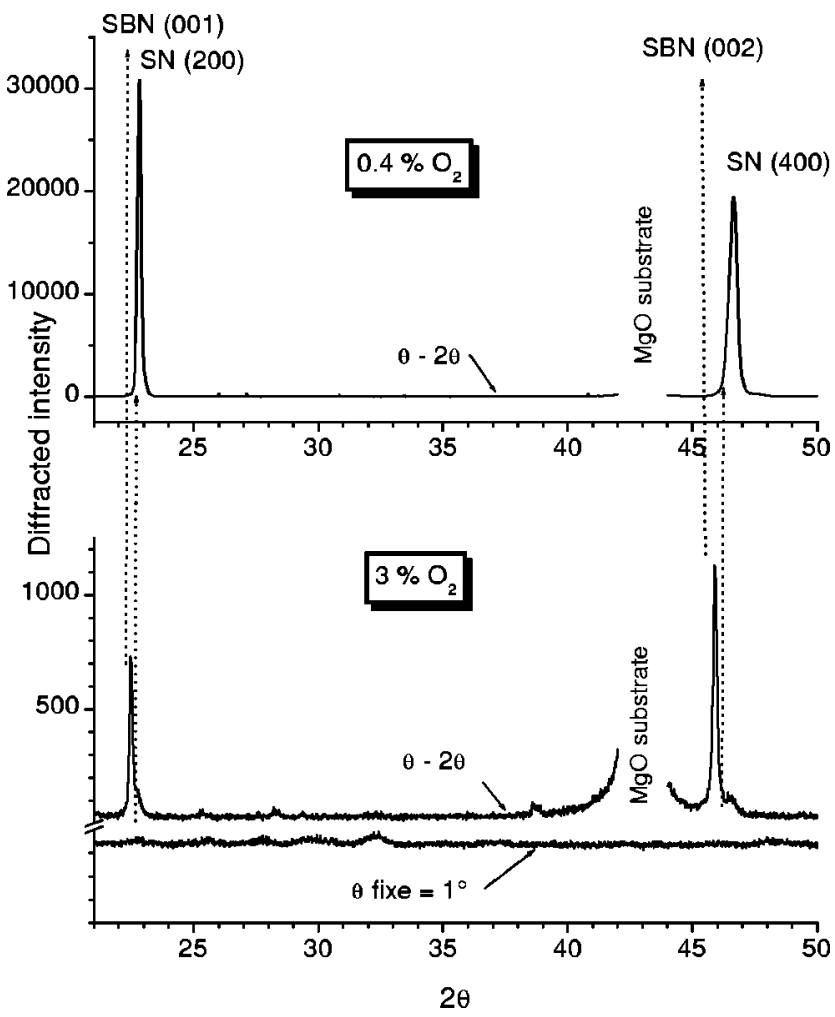

FIG. 8. XRD $\theta-2 \theta$ scans of two thin films prepared from a SBN:48 target by using the same deposition parameters except the oxygen percentage in the plasma. A scan recorded at fixed $\theta=1^{\circ}$ is also given for sample $3 \%$.

ichiometry is not sufficient to prevent the crystallization of a parasitic phase as SN which obviously collapses only for excessive $\mathrm{Nb}$ contents.

\section{Epitaxial growth of the SBN phase}

Back to a linear $y$ scale and to a more extensive angular range, two XRD spectra among the previous ones are shown in Fig. 8. The above-announced (200) orientation of the SN parasitic phase is well illustrated with the top spectrum $\left(0.4 \% \mathrm{O}_{2}\right)$. Evidence for the strong (001) orientation of the SBN phase is illustrated in the bottom part of Fig. 8 where both the $\theta-2 \theta$ scan and a fixed $\theta$ scan indicate that the SBN phase is completely (001) oriented. A rocking curve measurement at the SBN (001) $2 \theta$ location provides a full width at half maximum $\Delta \theta=2.6^{\circ}$.

XRD phi scans further demonstrate that SBN is epitaxially grown on $\mathrm{MgO}$. Two sets of planes have been probed, (211) and (311), selected on the basis of the high intensity they are expected to diffract at $2 \theta \approx 27.7^{\circ}$ and $32.1^{\circ}$, respectively (see Fig. 1). Typical experimental phi scan we obtained are shown in Figs. 9(a) (SBN-211) and 9(b) (SBN311). The only in-plane orientations we found which well account for both (211) and (311) results are mirror symmetric $\left( \pm 31^{\circ}\right)$ to the axis of the $\mathrm{MgO}(100)$ cell axis. The peak locations predicted from simulation for these two orientations are indicated in the figure with triangles. Four peaks are then not accounted for in each of these two phi scans. The closeness between the $(2 \theta, \psi)$ pairs of SBN $(211)$ and SN (202) well accounts for the four parasitic peaks pointed with circles in Fig. 9(a). A similar closeness between the $(2 \theta, \psi)$
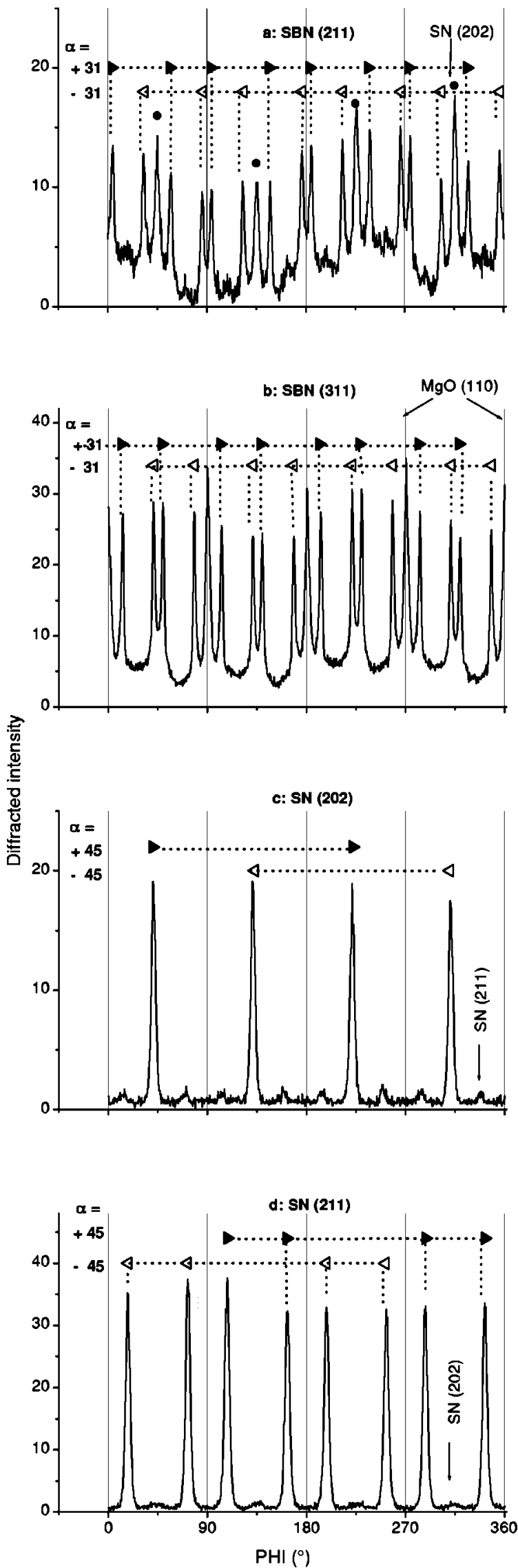

FIG. 9. Typical phi-scan measurements of the planes SBN (211), SBN(311), SN(202) and SN (211) obtained from thin films prepared by rf magnetron sputtering and close to SBN stoichiometry. 
pairs of SBN (311) and $\mathrm{MgO}$ (110) explains the four parasitic peaks in Fig. 9(b). Two sets of planes have been similarly probed to analyze the in-plane orientations of the SN phase, (202) and (211). As already mentioned and indicated in the figure with triangular symbols, two in-plane mirror symmetric orientations $\left( \pm 45^{\circ}\right)$ well account for both experimental phi scans. An explanation for this double epitaxy of $\mathrm{SBN}$ and $\mathrm{SN}$ on $\mathrm{MgO}$ may be found in the double quasialignment of (010) SN and (140) SBN planes with (011) $\mathrm{MgO}$ ones.

The assignment of the (001) and (002) intense experimental peaks to the TTB SBN phase rather than to the other possible competing phases $\left(\mathrm{S}_{2} \mathrm{~N}_{5}, \mathrm{BN}, \mathrm{BN}_{3}, \mathrm{~B}_{3} \mathrm{~N}_{5}\right)$ was until now only partially justified. The $r-1 / 2$ ratio $<1$ is not consistent with $\mathrm{S}_{2} \mathrm{~N}_{5}$ or $\mathrm{BN}_{3}$. The phi-scan measurements rule out the two remaining ambiguities. Neither of the $\mathrm{BN}$ and $\mathrm{B}_{3} \mathrm{~N}_{5}$ assumptions is able to account for both phi scans shown in Figs. 9(a) and 9(b).

\section{CONCLUSION}

In the work reported here, we have examined the ability of sputtering technique to deposit stoichiometric SBN thin films for use in integrated electro-optics. Composition analysis has enabled us to probe the mechanisms which control the target-film composition transfer and to define an experimental strategy for stoichiometry control. Epitaxial (001) SBN thin films have been obtained on $\mathrm{MgO}(100)$ substrates, which exhibit two in-plane orientations $\left( \pm 31^{\circ}\right)$ mirror sym- metric to the $\mathrm{MgO}$ cell axis. Stoichiometry is nevertheless insufficient to provide single phase SBN thin films.

${ }^{1}$ Z. Lu, S. Feigelson, R. K. Route, R. Hiskes, and S. A. Dicarolis, Mater. Res. Soc. Symp. Proc. 335, 59 (1994).

${ }^{2}$ M. J. Nystrom, B. W. Wessels, W. P. Lin, G. K. Wong, D. A. Neumayer, and T. J. Marks, Appl. Phys. Lett. 66, 1726 (1995).

${ }^{3}$ S. Schwyn Thöny, K. E. Youden, J. S. Harris, Jr., and L. Hesselink, Appl. Phys. Lett. 65, 2018 (1994).

${ }^{4}$ D. Trivedi, P. Tayebati, and M. Tabat, Appl. Phys. Lett. 68, 3227 (1996).

${ }^{5}$ M. Nakano, H. Tabata, K. Tanaka, Y. Katayama, and T. Kawai, Jpn. J. Appl. Phys., Part 2 36, L1331 (1997).

${ }^{6}$ K. Tanaka, O. Nakagawara, M. Nakano, T. Shimuta, H. Tabata, and T. Kawai, Jpn. J. Appl. Phys., Part 1 37, 6142 (1998).

${ }^{7}$ J. G. Zhu, S. K. Singh, P. A. Thomas, and S. B. Palmer, Philos. Mag. A 79, 2869 (1999).

${ }^{8}$ L. D. Zhu et al., Appl. Phys. Lett. 67, 1836 (1995).

${ }^{9}$ W. Sakamoto, T. Yogo, K. Kikuta, A. Kawase, and S. Hirano, J. Am. Chem. Soc. 79, 2283 (1996).

${ }^{10}$ J. Koo, J. H. Jang, and B.-S. Bae, J. Am. Chem. Soc. 84, 193 (2001).

${ }^{11}$ A. D. Li, C. L. Mak, K. H. Wong, D. Wu, and N. B. Ming, J. Mater. Res. 16, 3179 (2001).

${ }^{12}$ V. D. Antsigin, V. M. Egorov, E. G. Kostsov et al., Ferroelectrics 63, 235 (1985).

${ }^{13}$ R. R. Neurgaonkar et al., Mater. Res. Bull. 26, 983 (1991).

${ }^{14}$ C.-A. Jong and J.-Y. Gan, Jpn. J. Appl. Phys., Part 1 39, 545 (2000).

${ }^{15}$ Y. S. Yang, M. K. Ryu, H. J. Joo, S. H. Lee, S. J. Lee, K. Y. Kang, and M. S. Jang, Appl. Phys. Lett. 76, 3472 (2000).

${ }^{16}$ A. M. Prokhorov and Yu S. Kuz'minov, Ferroelectric Crystals for Laser Radiation Control (Adam Hilger, Boston, 1990), p. 81.

${ }^{17}$ P. B. Jamieson, S. C. Abrahams, and J. L. Bernstein, J. Chem. Phys. 48, 5048 (1968)

${ }^{18}$ J. R. Carruthers and M. Grasso, J. Electrochem. Soc. 117, 1426 (1970). 